\title{
İnsan karbonik anhidraz I,II izoenzim aktiviteleri üzerine bazı tiyocrown eterlerin etkisi
}

\author{
Ebru AKKEMİK ${ }^{1, *}$, Ümit ÇALIŞIR ${ }^{2,3}$, Baki ÇIÇEK ${ }^{3}$ \\ ${ }^{1}$ Siirt Üniversitesi, Mühendislik Mimarlık Fakültesi, Gıda Mühendisliği, Kezer kampüsü, Siirt \\ ${ }^{2}$ Siirt Üniversitesi, Bilim ve Teknoloji Uygulama ve Araştırma Merkezi, Kezer kampüsü, Siirt \\ ${ }^{3}$ Balıkesir Üniversitesi, Fen Edebiyat Fakültesi, Kimya Bölümü, Çă̆ış kampüsü, Balıkesir
}

Geliş Tarihi (Recived Date): 30.07.2017

Kabul Tarihi (Accepted Date): 15.09.2017

\section{Özet}

Metalo enzim sinıfinın bir üyesi olan karbonik anhidrazlar karbondioksitin bikarbonata ve protona dönüşümünü katalizlerler. Bir çok izoenzime sahip olan karbonik anhidrazların inhibisyonu veya aktivasyonu fizyolojik açıdan oldukça önemlidir. Bu yüzden bizde çalışmamızda insan eritrositlerinden karbonik anhidraz I ve II izoenzimini saflaştırdık. Saflaştırdığımız enzim aktiviteleri üzerinde bazı tiyoeter türevlerinin $(1,10$ ditiyo-18-crown-6 (B1), 1,7-ditiyo-15-crown-5 (B2), 1,7- ditiyo-12-crown-4 (B3), 1,7ditiyo-18-crown-6 (B4), 1,10-ditiyo-21-crown-7 (B5) ve 1,4-ditiyo-12-crown-4 (B6)) etkilerini in vitro şartlarda araştırdık. B1 ve B5 her iki izoenzim aktivitesi üzerinde düzenli bir etki göstermezken, en iyi aktivasyon etkisini her iki izoenzim için B2 bileşiği ( $h C A$ I için $A C_{50}=25.27 \mu M$ ve hCA II için $\left.A C_{50}=32.74 \mu M\right)$ göstermiştir.

Anahtar kelimeler: Karbonik anhidraz, tiyocrown, aktivasyon.

\section{Effects of some thio-crown ethers on human erythrocyte carbonic anhydrase I-II isozymes activities}

\begin{abstract}
Carbonic anhydrases, a member of the class of metalloenzymes, catalyze the conversion of carbon dioxide to bicarbonate and proton. The inhibition or activation of carbonic anhydrases having many isoenzymes is of great physiological importance. That's why we have purified carbonic anhydrase I and II isoenzymes from human erythrocytes. On the activities of the purified enzymes we investigated that effects some thioether $(1,10$ -
\end{abstract}

\footnotetext{
*Ebru AKKEMIK, eakkemik@siirt.edu.tr, https://orcid.org/0000-0002-4177-4884

Ümit ÇALIŞIR, umitcalisirr@gmail.com, https://orcid.org/0000-0001-7699-2008

Baki ÇIÇEK, bcicek@ balikesir.edu.tr, https://orcid.org/0000-0003-1257-1188
} 
dithia-18-crown-6 (B1), 1,7-dithia-15-crown-5 (B2), 1,7-dithia-12- (B3), 1,7-dithia-18crown-6 (B4), 1,10-dithia-21-crown-7 (B5) and 1,4-dithia-12-crown-(B6)) derivatives in in vitro conditions. $B 1$ and $B 5$ did not show any regular effect on both isoenzyme activity. The best activation effect has been the B2 compound (for $h C A I, A C_{50}=$ 25.27 $\mu M$, and for $h C A$ II, $\left.A C_{50}=32.74 \mu M\right)$ for both isoenzymes.

Keywords: Carbonic anhydrases, thio crown, activation.

\section{Giriş}

Bütün organizmalarda bulunan ve yapısında $\mathrm{Zn}^{2+}$ iyonu içeren karbonik anhidrazlar (CA, E.C.4.2.1.1), canlilarda $\mathrm{CO}_{2}$ 'in hidratasyonunu ve $\mathrm{HCO}_{3}^{-1}$ in dehidratasyonunu katalizlizler [1-3]. Şu ana kadar karbonik anhidraz'ın 16 farklı izoenzimi bulunmuştur. Katalitik olarak aktif insan $\alpha$-CA'larının hücre içi yerleşimleri ve bölge kompozisyonları incelendiğinde, CA I, II, III, VII ve XIII sitozolik, CA VA, VB mitokondriyal, CA VI salgısal, CA IV, IX, XII ve XIV ise membrana bağlı olduğu belirtilmiştir [3, 4].

CA'lar fizyolojik açıdan oldukça önemlidir. CA'lar pek çok dokuda asit-baz dengesini sağlayarak pH düzenleyici enzim olarak karakterize edilmiş̧lerdir. Ayrica üre sentezi, lipogenez, glukoneogenez, gibi biyosentetik reaksiyonlarda görev almalarının yanı sıra kalsifikasyon, tümör oluşumu gibi birçok fizyolojik ve patolojik olayda da görev alırlar [5-7]. Oldukça önemli fizyolojik ve patolojik süreçlerde görev almasının sonucu olarak ödem, glokom, obezite, kanser, epilepsi ve osteoporozis, alzheimer gibi hastalıkların tedavisinde CA inhibitörleri yada aktivatörleri potansiyel tedavi edici hedefler olarak görülmektedir [8-12].

Karbonik anhidrazların inhibisyonu kadar aktivasyonlarıda son derece önemlidir. Karbonik anhidraz izoenzimlerinin turnover sayıları çok yüksek olmasına rağmen olması muhtemel genetik bir rahatsızlık neticesinde karbonik anhidrazların aktivasyonu gerekli olacaktır. Karbonik anhidraz enziminin genetik eksikliği çeşitli patolojik ve fizyolojik hastalıklara sebep olabileceği ve bununda ancak CA aktivatörleri ile ortadan kalkabileceği belirtilmiştir [13-17]. Dahası son zamanlardaki çalışmalarda alzheimer hastalığının tedavisi için CA aktivatörlerinin kullanılabileceğini belirtmektedir [18].

Çalışma konusu olan crown (taç) eterler, dioksan molekülünün halkalı oligomerleri olarak görülebilecek makrohalkalı bileşiklerdir [19]. Yüksek konformasyonal esnekliği, pozitif yüklü katyonları bağlayabilen hidrofilik bir boşluk ile dış kısmı hidrofobik özellik gösteren esnek bir yap1 sayesindedir [20]. Moleküler dizayn, supramoleküler kimya, analitik kimya ve ilaç alanlarında taç eter kullanımı hakkında çok çeşitli araştırmalar yapılmaktadır [21]. Sonuç olarak çeşitli crown eter türevlerinin ilaç yada ön ilaç olarak değerlendirilebileceği bir çok çalışmada belirtilmiştir [22-24].

$\mathrm{Bu}$ çalışma da insan karbonik anhidraz I ve II'nin aktivatörleri olabileceğini düşündüğümüz tiyo-crown eter türevlerinin etkileri in vitro şartlar altında araştırılmıştır. 


\section{Deneysel çalışmalar}

\subsection{Kullanilan kimyasal maddeler ve cihazlar}

Sepharose-4B, asetik asit ve elektroforez için kullanılan kimyasal maddeler SigmaAldrich Co.'dan (Sigma-Aldrich Chemie GmbH İhracat Departmanı Eschenstrasse 5, 82024 Taufkirchen, Almanya) elde edildi. Saf etanol ve L-tirozin, E. Merck (Merck KGaA Frankfurter strasse 250, D-64293 Darmstadt Germany) 'den elde edildi. Kullanılan diğer kimyasal maddeler Sigma-Aldrich ya da E. Merck'den elde edilmiştir. Tüm kinetik çalışmalar Evolution 201 UV-Visible Spectrophotometer (Thermo Scientific)'de gerçekleştirilmiştir.

\subsection{Kimyasal çalışma}

Çalışmada kullanılan kimyasal bileşikler; 1,10-dithia-18-crown-6 (B1), 1,7-dithia-15crown-5 (B2), 1,7-dithia-12-crown-4 (B3), 1,7-dithia-18-crown-6 (B4), 1,10-dithia-21crown-7 (B5) ve 1,4-dithia-12-crown-4 (B6) ekibimiz tarafindan daha önce sentezlenmiş ve karakterize edilmiştir (Şekil 1) [25].

\subsection{Biyokimysal çalışma}

Taze insan eritrositi buzlu saf su ile (1x5 oranında) karıştırılarak hemoliz edildi. Elde edilen hemolizat $+4^{\circ} \mathrm{C}$ de $30.000 x g$ de 30 dakika santrifüj edildi. Hücre membranlarını içeren çökelek uzaklaştırıldı. Elde edilen süpernatantın pH'ı katı Tris ile 8.7 ayarlandı. Daha önceki çalışmalarda belirttiğimiz gibi Sefaroz-4B-L-tirozin sülfanilamit afinite kolon kromatografisi yardımıyla karbonik anhidraz I ve II izoenzimleri saflaştırıldı [26]. Bunun için ilk olarak $25 \mathrm{mM}$ Tris- $\mathrm{HCl} / 100 \mathrm{mM} \mathrm{Na}_{2} \mathrm{SO}_{4}$ (pH: 8.7) tamponu ile dengelenen afinite kolonuna hemolizat yüklendi. Sonra $280 \mathrm{~nm}$ deki absorbans fark1 0.050 oluncaya kadar $25 \mathrm{mM}$ Tris- $\mathrm{HCl} / 22 \mathrm{mM} \mathrm{Na}_{2} \mathrm{SO}_{4}(\mathrm{pH}$ 8.7) tamponu ile afinite kolonu iyice yıkandı. Böylece $\mathrm{CA}$ izoenzimleri kolana bağlanırken diğer enzimler ve safsızlıklar uzaklaştııılmış oldu. hCA I izoenzimi $1.0 \mathrm{M} \mathrm{NaCl} / 25 \mathrm{mM} \mathrm{Na} \mathrm{HPO}_{4}(\mathrm{pH}$ 6.3) ile hCA II izoenzimi ise $0.1 \mathrm{M} \mathrm{NaCH}_{3} \mathrm{COO} / 0.5 \mathrm{M} \mathrm{NaClO}_{4}$ (pH 5.6) tamponu ile elüe edildi. Tüm çalışmalar $+4^{\circ} \mathrm{C}$ yürütüldü. Kolonun akış hızı ise çalışma boyunca 35 $\mathrm{mL} / \mathrm{h}$ olacak şekilde ayarlandı. Enzimlerin elüsyonu $280 \mathrm{~nm}$ de absorbans bakılarak kontrol edildi. Absorbans görülen fraksiyonlar birleştirilerek $0.05 \mathrm{M}$ Tris-SO $\mathrm{SO}_{4}(\mathrm{pH}$ 7.4) tamponuna karşı diyaliz edildi [26].

Enzim saflığı Laemmli'nin prosedürüne göre SDS-PAGE ile kontrol edildi [27]. Her iki izoenzim içinde tek band gözlendi (Şekil 2). Standart proteinlerin molekül kütlesi;180, 130, 95, (kırmızı) 72, 55, 43, 34, 26, 17 kDa şeklindedir. Bu çalışmada karbonik anhidraz enziminin estaraz aktivitesi kullanıldı. Bu metotta karbonik anhidraz pnitrofenol asetatı substrat olarak kullanarak hidroliz eder ve p-nitrofenol oluşturur, oluşan ürün $348 \mathrm{~nm}$ de absorbans vermektedir [28]. Bu sayede CA aktivitesine bakılmış oldu.

İnsan eritrositlerinden saflaştırılan CA'ın izoenzimlerinin aktiviteleri üzerine B1-B6 bileşiklerinin etkileri in vitro şartlarda araştırıldı. Sentezlenen bileşiklerin her birinin beş farklı konsantrasyonunda enzim aktivitesi bakıldı. Bileşik içermeyen aktivite ölçümü kontrol olarak kabul edildi (\%100 aktivite). B1-B6 bileşiklerinin konsantrasyonlarına karş1 \% aktivite grafiği çizildi. Elde edilen grafikten $\mathrm{AC}_{50}$ değerleri tespit edildi. 


\section{Sonuçlar ve tartışma}

Çalışmamızda insan karbonik anhidraz enzim aktivitesi üzerinde etkileri incelenen bileşikler ekibimiz tarafından daha önce sentezlenmiş ve karakterize edilmiştir (Şekil 1) [25].

\begin{tabular}{lll} 
Ligand & $\mathrm{y}$ & $\mathrm{z}$ \\
\hline B1 & 2 & 0 \\
B2 & 1 & 1 \\
B3 & 2 & 1 \\
B4 & 1 & 3 \\
B5 & 2 & 2 \\
B6 & 2 & 3
\end{tabular}

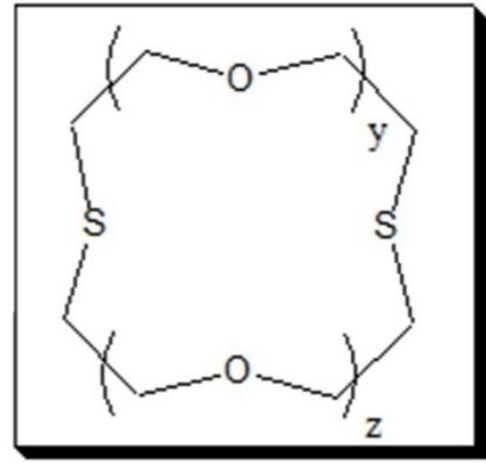

Şekil 1. Çalışmamızda kullanılan tiyo-crown eter türevleri [25].

Karbonik anhidraz enziminin I ve II izoenzimleri insan eritrositlerinden saflaştırıldı. Enzimin saflaştırıldığı SDS-PAGE ile kontrol edildi (Şekil 2). Karbonik anhidraz enzimi daha önce ekibimiz tarafından bir çok kez saflaştırılmıştır [29]. Şekil 2'den de anlaşılacağı üzere karbonik anhidraz enziminin her iki izoenzimi başarıyla saflaştırılmıştır.

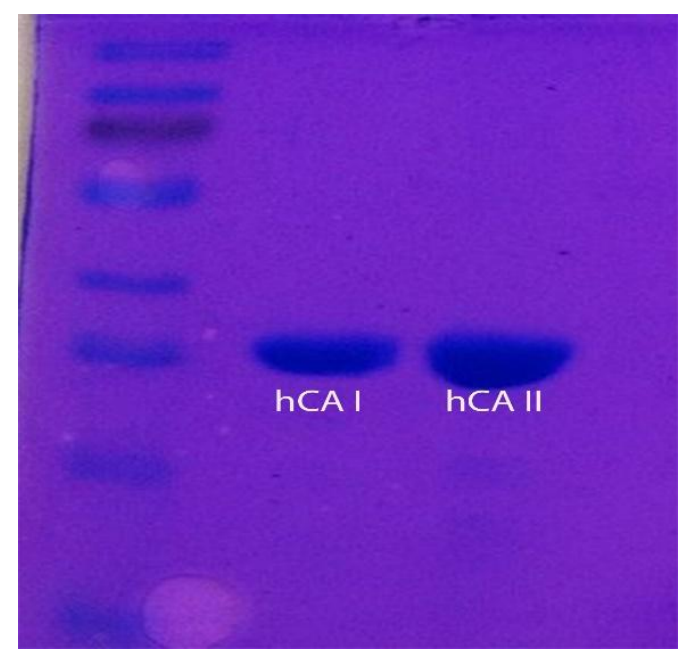

Şekil 2. İnsan karbonik anhidraz I veII enziminin saflığının SDS-PAGE ile kontrolü.

İnsan eritrositlerinden saflaştırılan karbonik anhidrazın her iki izoenziminin aktivitesi üzerine B1, B2, B3, B4, B5 ve B6 bileşiklerinin etkileri araştırılmıştır (Şekil 3, Tablo 1). B1 ve B5 bileşiği her iki izoenzim aktivitesi üzerinde düzenli bir etki göstermezken, B6 bileşiği sadece hCA I'i aktive etmiştir. B2, B3 ve B4 bileşikleri ise her iki izoenzimi de aktive etmişlerdir. B2, B3, B4 ve B6'nın hCA I için AC $_{50}$ değerleri sırasıyla 25.27, 127.4, 596.7 ve $323.3 \mu \mathrm{M}$ olarak tespit edilmiştir (Tablo 1). Elde edilen veriler incelendiğinde en yüksek aktivasyonu B2 gösterirken en düşük aktivasyonu B4 göstermektedir. B2, B3 ve B4'ün hCA II için $\mathrm{AC}_{50}$ değerleri sırasıyla 32.74, 431.0 ve 
$848.8 \mu \mathrm{M}$ olarak tespit edilmiştir (Tablo 1). Yine aynı şekilde hCA II içinde en yüksek aktivasyonu B2 gösterirken en düşük aktivasyonu B4 göstermektedir.
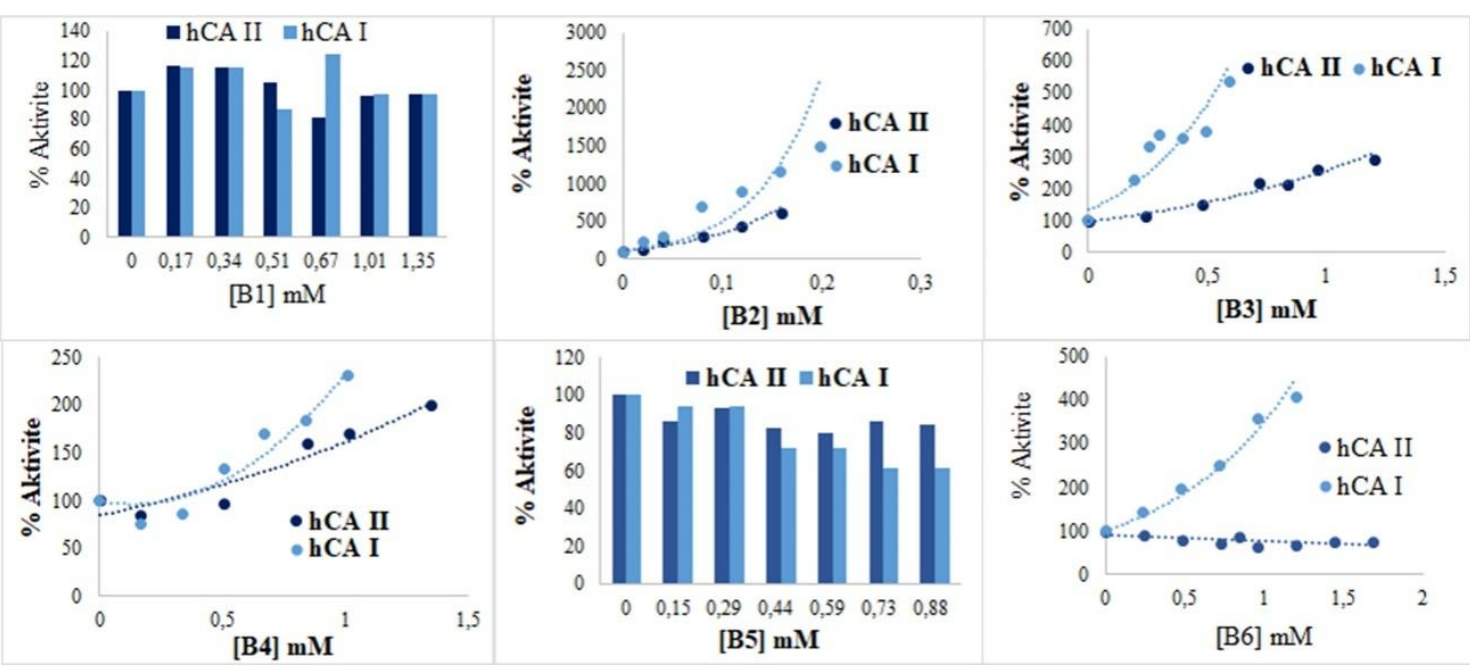

Şekil 3.Tiyo crown eterlerin hCA I-II enzim aktiviteleri üzerindeki etkisi.

16 farklı izoenzime sahip olan karbonik anhidrazın katalitik aktiviteye sahip olan her bir izoenzimi için bu güne kadar çok sayıda aktivayon çalışmaları yapılmıştır. Örneğin CA III'ün anyonik aktivatörleri olduğu [31] CA I, II, IV'ün çeşitli organik bileşikler tarafından aktive olduğu belirtilmiştir [32-34]. Yapılan başka bir çalışmada histidin tarafından CA II'nin aktive olduğu belirtilmiştir [35]. Görüldüğü gibi çok sayıda aktivasyon çalışmaları mevcuttur. Bunun asıl nedeni birçok fizyolojik prosesle ilişkili olan CA'ların inhibisyonun ya da aktivasyonunun hastalık tedavisinde kullanılabileceği gerçeğidir. Özellikle CA'ların aktivasyonunun alzheimer tedavisinde etkili olabileceğini gösteren çalışmalar araştırmacıları bu alana yönlendirmiştir [18].

Tablo 1. Tiyo-crown eterlerin hCA I-II enzim aktiviteleri üzerindeki aktivasyon etkisi.

\begin{tabular}{ccccc}
\hline Bileşikler & \multicolumn{5}{c}{$\mathbf{A C}_{\mathbf{5 0}}(\boldsymbol{\mu M})$} \\
\hline & hCA-I & $\mathbf{R}^{2}$ & $\mathbf{h C A}-\mathbf{I I}$ & $\mathbf{R}^{2}$ \\
\hline B1 & - & - & - & - \\
$\mathbf{B 2}$ & 25.27 & 0.8038 & 32.74 & 0.9362 \\
$\mathbf{B 3}$ & 127.4 & 0.7641 & 431.0 & 0.9527 \\
$\mathbf{B 4}$ & 596.7 & 0.9297 & 848.8 & 0.7739 \\
$\mathbf{B 5}$ & - & - & - & - \\
$\mathbf{B 6}$ & 323.3 & 0.9835 & - & - \\
\hline
\end{tabular}

Ligandların aktivasyon göstermesini crown eterlerin temel yapısının fonksiyonu olarak metallere olan ilgisi ile açıklayabiliriz. Crown eterler genel olarak metal iyonları ile zayıf van der waals etkileşimleri kurarlar. $\mathrm{Bu}$ etkileşimler sayesinde de metaloenzimlerin yapısını bozabilirler. Aynı ligandlar ile yapılan bir diğer çalışmada kloroform ve diklorometan çözeltileri içerisinde metal bağlama özellikleri incelendiğinde genel olarak ligantların çinko metaline de ilgi gösterdiği tespit edilmiştir [30]. Örneğin enzimlerin aktif bölgeleri metal iyonu içerir (hCA I ve II'de çinko metal iyonu, $\left.\mathrm{Zn}^{2+}\right)$. Bu metal iyonlarını zayıf etkileşimler ile büyük enzim kompleks yapılarından dışarı çıkarabilirler. Ya da halkalı yapısı gereği iç kısımlarında içerdikleri 
oyuk vasıtasıyla enzimlerin substrat ile olan buluşmasını hızlandırabilirler. Substratın enzimle etkileşim hızının artması ile enzimlerin aktivitesi de artabilir (Şekil 4).

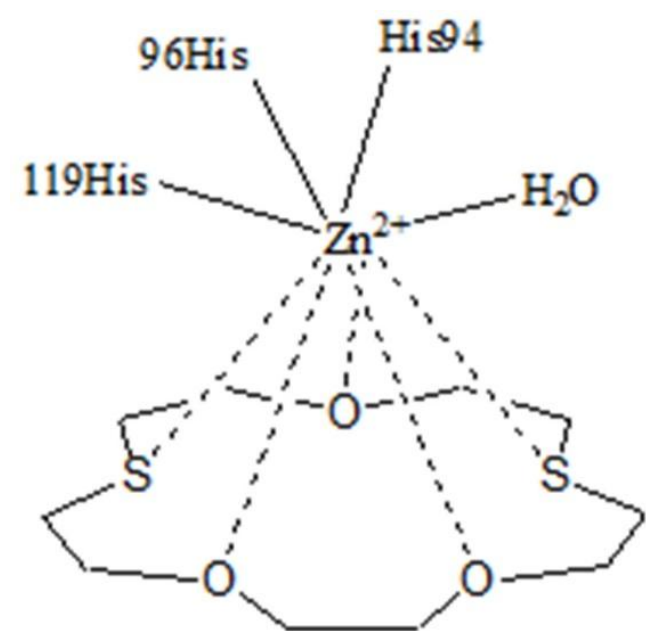

Şekil 4. Genel olarak tiyo-crown eterlerin aktivasyon mekanizması.

Sonuçlar incelendiğinde hCA I-II aktivasyonları arasında farklılıklar gözlenmektedir. $\mathrm{Bu}$ durum ligandların kimyasal yapısıyla açıklanabilir. Genel olarak tüm ligandlar iki kükürt atomu ve değişen sayıda oksijen atomu içermektedir. Ancak hCA I ve hCA II aktiviteleri üzerinde meydana gelen farklılıklar oksijen atomu sayısı ve kükürt atomlarının pozisyonundan kaynaklanmaktadır. Örneğin 1,7-ditiyo crown eterler 1,4- ve 1,10-ditiyo crown eterlere göre daha yüksek aktivasyon göstermektedir. $\mathrm{Bu}$ durum kükürt atomlarının oksijenlere göre oldukça hacimli yapıya sahip olmaları, birbirlerine olan yakınlık ve uzaklıklarına göre aktivasyonu artırmakta ve azaltmaktadır. Bu atomların uzaklıkları halka kavitelerini etkilemektedir. Daha önceki çalışmalarda bu bileşiklerin halka kaviteleri hakkında bilgi sağlayan moleküler orbital diyagramları ve enerji değerleri hesaplanmıştır [25]. Bu değerlere sahip ligandlar ile enzimleri aktive eden bileşikler yaklaşık olarak benzerlik göstermektedir. B2-B3 ve B4 ligandları benzer kaviteye sahip olmaları sebebiyle CA'ın her iki izoenzimi üzerinde aktivasyon etkisine sahiptirler.

\section{Kaynaklar}

[1] Maren, T.H., Carbonic anhydrase; chemistry, physiology and inhibition, Phsiological Reviews, 47, 595-781, (1967).

[2] Supuran, C.T., and Scozzafava, A., Carbonic Anhydrase Inhibitors, Current Medicinal Chemistry, 1, 61-97, (2001).

[3] Nar, M., Rozmarinik asitin antioksidan kapasitesinin belirlenmesi ve insan karbonik anhidraz izoenzimleri (hCA-I VE hCA-II) üzerine inhibisyon etkisinin incelenmesi. Yüksek Lisans Tezi, Atatürk Üniversitesi, Fen Bilimleri Enstitüsü, Erzurum, (2011).

[4] Supuran, C.T., Carbonic anhydrases: catalytic and inhibition mechanisms, distribution and physiological roles. In carbonic anhydrase. Its inhibitors and activators (Supuran, C.T., Scozzafara, A. and Conway, J., eds), CRC Press, London, 1-23, (2004).

[5] Chegwidden, W.R., Edwards, Y. and Carter, N., The Carbonic anhydrase-new horizons molecular bases of inherited disease (Scriver, C.R., Beaudet, A.L., Sly, 
W.S., and Valle, D.) 8th Edition, 2165-2204, McGraw-Hill Education., Newyork, (2000).

[6] Supuran, C.T., Scozzafava, A., Casini, A., Mincione, F., Menabuoni, L., Caproiu, M.T., Maganu, M. and Banciu, M.D., Carbonic anhydrase inhibitors: sulfonamides incorporating furan-thiophene- and pyrrole-carboxamido groups possess strong topical intraocular pressure lowering porperties as aqueous suspensions, Biororganic and Medicinal Chemistry, 8, 2145-2155, (2000).

[7] Supuran, C.T., and Scozzafava, A., Carbonic Anhydrase Inhibitors, Current Medicinal Chemistry, 1, 61-97, (2001).

[8] De Simone, G. and Supuran, C.T., Antiobesity carbonic anhydrase inhibitors, Current Topics in Medicinal Chemistry, 7, 9, 879-84, (2007).

[9] Wolfensberger, T.J., The role of carbonic anhydrase inhibitors in the management of macular edema, Documenta Ophthalmologica, 97, 387-397, (1999).

[10] Pastorekova, S., Zatovicova, M., and Pastorek, J., Cancer-Associated Carbonic Anhydrases and Their Inhibition, Current Pharmaceutical Design, 14, 685698, (2008).

[11] Dilek, E., Activation of Two Different Drugs Used in Alzheimer's Disease Treatment on Human Carbonic Anhydrase Isozymes I and II Activity: an In Vitro Study, Turkish Journal of Pharmaceutical Sciences, 14, 2, 164-168, (2017).

[12] Aggarwal, M., Kondeti, B. and McKenna, R., Anticonvulsant/antiepileptic carbonic anhydrase inhibitors: a patent review, Expert Opinion on Therapeutic Patents, 23, 6, 717-24, (2013).

[13] Roth, D.E., Venta,P.J., Tashian, R. E. and Sly, W. S., Molecular basis of human carbonic anhydrase II deficiency, National Academy of Sciences of the United States of America, 89, 5, 1804-8, (1992).

[14] DeCoursey, T.E., Hypothesis: do voltage-gated $\mathrm{H}(+)$ channels in alveolar epithelial cells contribute to $\mathrm{CO}(2)$ elimination by the lung?, American Journal of Physiology - Cell Physiology, 278, 1, C1-C10, (2000).

[15] Rousselle, A.V., and Heymann, D., Osteoclastic acidification pathways during bone resorption, Bone, 30, 4, 533-540, (2002).

[16] Sun, M.K., and Alkon, D.L., Carbonic anhydrase gating of attention: memory therapy and enhancement, Trends in Pharmacological Sciences, 23, 2, 83-9, (2002).

[17] Alper, S.L., Genetic diseases of acid-base transporters., Annual Review of Physiology, 64, 899-923, (2002).

[18] Supuran, C.T., Carbonic anhydrases: novel therapeutic applications for inhibitors and activators, Nature Reviews Drug Discoveryvol, 7, 2, 168-81, (2008).

[19] Kiraz, A., Yeni tür Schiff bazı taç eter ligandlarının sentezi, kompleksleri ve yapılarının incelenmesi”, Doktora Tezi, Çanakkale Onsekiz Mart Üniversitesi Fen Bilimleri Enstitüsü, Çanakkale, (2008).

[20] Bulut, N.V., Taç eter türevi bir makrosiklik bileşik kullanılarak değişik matrikslerde altın'ın zenginleştirilmesi ve spektrofotometrik tayini”, Doktora Tezi, Karadeniz Teknik Üniversitesi Fen Bilimleri Enstitüsü, Trabzon, (2009).

[21] Xiao, L., Molecular characterization of drug/drug carrier interaction through investigation on a crown ether/ cation system,686, University of Wisconsin-Madison, (2006). 
[22] Darwish, I.A. and Uchegbu, I.F., The evaluation of crown ether based niosomes as cation containing and cation sensitive drug delivery systems, International Journal of Pharmaceutics, 159, 207-213, (1997).

[23] Dumont, B., Joly, J.P., Chapleur, Y. and Marsura., A., New Oligosaccharidic Crown Ethers as Potential Drug-Targetting Vectors: Synthesis \& Biological Evaluation. Bioorganic and Medicinal Chemistry Letters, 4, 1123-1126, (1994).

[24] Coppola, C., Simeone, L., Trotta, R., De Napoli, L., Randazzo, A. and Montesarchio, D., Synthesis and NMR characterization of a novel crown-ether ring-fused uridine analogue. Tetrahedron, 66, 6769-6774,(2010).

[25] Çiçek, B. and Yıldız, A., Synthesis, Metal Ion Complexation and Computational Studies of Thio Oxocrown Ethers, Molecules 16, 8670-8683,(2011).

[26] Huyut, Z., Beydemir, S. and Gülçin, I., Inhibition properties of some flavonoids on carbonic anhydrase I and II isoenzymes purified from human erythrocytes., Journal of Biochemical and Molecular Toxicology, 21930, (2017).

[27] Laemmli, U.K., Cleavage of structural proteins during the assembly of the head of bacteriophage T4. Nature 227, 680-5,(1970).

[28] Verpoorte, J., Mehta, S. and Edsall, J.T., Esterase activities of human carbonic anhydrases B and C. The Journal of Biological Chemistry, 242, 4221-4229, (1967).

[29] Akkemik, E., Camadan, Y., Cicek, B., Calisir, U. and Onbasioglu, Z., The determination of the carbonic anhydrases activators, The FEBS Journal, 283: P-09.02.2-020, (2016).

[30] Çiçek, B., and Çalışır, Ü., The Investigation of Complexation Properties and Hard-Soft Acid-Base Relationship Between Thiacrown Ethers and Metal Ions, Letters in Organic Chemistry, 13, 572-577, (2016).

[31] Shelton, J.B. and Chegwidden, W.R., Activation of carbonic anhydrase III by phosphate, Biochemical Society Transactionsvol, 16, 5, 853-854,(1988).

[32] Banciu, C. and Puscas, I., Carbonic Anhydrase And Modulation of Physiologic And Pathologic Processes In the Organism: Enzime [sic] Activators And Inhibitors, 593, Timisoara: Editura Helicon, 1994.

[33] Scozzafava, A., Briganti, F., Ilies, M.A. and Supuran, C.T.,Carbonic Anhydrase Inhibitors: Synthesis of Membrane-Impermeant Low Molecular Weight Sulfonamides Possessing in Vivo Selectivity for the Membrane-Bound versus Cytosolic Isozymes I, Journal of Medicinal Chemistry, 43, 2, 292-300, (2000).

[34] Supuran, C., Scozzafava, T. and. Casini, A., Carbonic anhydrase inhibitors, Medicinal Research Reviews., 23, 2,146-89, (2003).

[35] Silverman, D.N., Tu, C. and Wynns, G.C., Proton transfer between hemoglobin and the carbonic anhydrase active site, The Journal of Biological Chemistry., 253, 8, 2563-2567, (1978). 